\title{
Particle emissions from a modern heavy-duty diesel engine as ice- nuclei in immersion freezing mode: an experimental study on fossil and renewable fuels
}

Kimmo Korhonen ${ }^{1}$, Thomas Bjerring Kristensen ${ }^{2}$, John Falk ${ }^{2}$, Vilhelm B. Malmborg ${ }^{3}$, Axel Eriksson ${ }^{3}$, Louise Gren ${ }^{3}$, Maja

5 Novakovic $^{4}$, Sam Shamun ${ }^{4}$, Panu Karjalainen ${ }^{5}$, Lassi Markkula ${ }^{5}$, Joakim Pagels ${ }^{3}$, Birgitta Svenningsson ${ }^{2}$, Martin Tunér ${ }^{4}$, Mika Komppula $^{6}$, Ari Laaksonen ${ }^{7,1}$ and Annele Virtanen ${ }^{1}$

${ }^{1}$ University of Eastern Finland, Dept. of Applied Physics. P.O. box 1627, FI-70211 Kuopio, Finland

${ }^{2}$ Lund University, Department of Physics, P.O. box 118, SE-22100, Lund, Sweden

$10{ }^{3}$ Lund University, Ergonomics and Aerosol Technology, P.O. box 118, SE-22100, Lund, Sweden

${ }^{4}$ Lund University, Division of Combustion Engines, P.O. box 118, SE-22100, Lund, Sweden

${ }^{5}$ Tampere University, P.O. box 1001, FI-33014, Tampere, Finland

${ }^{6}$ Finnish Meteorological Institute, Atmospheric Research Centre of Eastern Finland, P.O. box 1627, FI-70211 Kuopio, Finland

${ }^{7}$ Finnish Meteorological Institute, P.O. box 503, FI-00101, Helsinki, Finland

15 Correspondence to: Kimmo Korhonen (Kimmo.korhonen@uef.fi)

\begin{abstract}
We studied ice-nucleating abilities of particulate emissions from a modern heavy-duty diesel engine using three different types of fuel. The polydisperse particle emissions were sampled during engine operation and introduced to a continuous-flow diffusion chamber (CFDC) instrument at a constant relative humidity $R H_{\text {water }}=110 \%$, and temperature was ramped between $-43{ }^{\circ} \mathrm{C}$ and $-32{ }^{\circ} \mathrm{C}$ (T-scan). The tested fuels were EN 590 compliant low-sulfur fossil diesel, hydrotreated vegetable oil (HVO) and rapeseed methyl ester (RME), and all were investigated without blending. Sampling was carried out at different stages in the engine exhaust after-treatment system, with and without simulated atmospheric processing using an oxidation flow reactor. In addition to ice-nucleation experiments, we used supportive instrumentation to characterize the emission particles and present six different physical and chemical properties of them. We found that the studied emissions were poor ice-nucleators and substitution of fossil diesel with renewable fuels, using different emission after-treatment systems
\end{abstract} and photochemical aging of total exhaust had only little effect on their ice-nucleating abilities.

\section{Introduction}

Atmospheric aerosols affect the radiative forcing budget of the Earth and thus climate in multiple different ways, directly through absorption/scattering of radiation and indirectly through impacts on cloud properties. Many direct effects are being routinely monitored through a global network of ground-based instruments. The indirect effects, however, remain less understood (Boucher et al, 2013) due to complexity of the processes that contribute to their final effects. One indirect effect of the aerosol particles is related to mixed-phase clouds (MPCs), where certain types of particles may promote formation of ice crystals within them. Understanding mixed-phase cloud processes is of utmost importance as cloud lifetimes and their radiative 
properties depend strongly on the cloud phase (Murray et al., 2012). Furthermore, most precipitation events on a global scale are initiated through ice processes in clouds (Mülmenstädt et al., 2015).

Homogeneous freezing of cloud droplets requires a temperature of approximately $-38{ }^{\circ} \mathrm{C}$ (Pruppacher and Klett, 1997). However, previous studies (viz. Despres et al., 2012; Hoose and Möhler, 2012) have shown that atmospheric aerosol particles, both of natural and anthropogenic origins, can induce ice formation in much higher temperatures than required for homogeneous ice-nucleation. Particles that are ice-active at $-30{ }^{\circ} \mathrm{C}$ are relatively rare in the lower troposphere with number concentrations on the order of $0.01 \mathrm{~cm}^{-3}$ in many regions (DeMott et al., 2010), but there is evidence that combustion emissions from different hydrocarbon fuels can have potential as active ice-nucleating particles in temperatures higher than that. For instance, soot particles from combustion of acetylene (DeMott, 1990), kerosene (Diehl and Mitra, 1998) and a soot generator (Gorbunov et al., 2001) have been reported to be active INPs at $-24{ }^{\circ} \mathrm{C},-20^{\circ} \mathrm{C}$ and $-10{ }^{\circ} \mathrm{C}$, respectively, in immersion and condensation freezing. On the contrary, there are multiple studies reporting a wide range of soot particles being inefficient

45 INPs (Kanji et al., 2020; Hoose and Möhler, 2012, and references therein). In most of those past ice-nucleation studies of soot particles, little if any information about the aerosol particle properties is provided. Korhonen et al. (2020) reported that the immersion freezing ability of freshly emitted soot particles from biomass combustion depended on minor differences in the combustion conditions, but their analysis on six different physicochemical properties of the studied particles revealed no correlation to their ice-nucleating ability. In addition to that, atmospheric aging processes may change the ice-nucleating (IN)

50 abilities of different soot particles (Mahrt et al., 2018; Häusler et al., 2018). These studies taken altogether show that it is currently very challenging to constrain the INP population associated with ambient soot particle populations.

The inconsistency in reported observations on soot IN abilities implies that it is unclear which types of soot are efficient INPs, and it has been addressed by multiple studies such as Bond et al. (2013). In addition to that, the Intergovernmental Panel of 55 Climate Change (IPCC) have encouraged for more studies that particularly focus on the INP potential of soot in their Fifth Assessment Report (Boucher et al, 2013). This uncertainty reflects to available parameterizations estimating the IN ability of the soot, causing them to range several orders of magnitude (Vergara-Temprado et al., 2018). Consequently, it leads to challenges when the potential effect on radiative forcing budget is estimated via modelling; for instance, the immersion freezing climate forcing due to anthropogenic soot particles has been reported to span from $0.1 \mathrm{~W} \mathrm{~m}^{-2}$ to $1 \mathrm{~W} \mathrm{~m}^{-2}$, depending on their ice-nucleating ability (Yun et al., 2013).

The diesel engine is the most widely used internal combustion engine type in transportation of goods globally (Davis et al., 2017). The popularity of this engine type increased significantly after the 1930s when outdated coal-fired steam engines became largely replaced by diesels particularly in heavy-duty engines, such as ones used in rail and marine traffic. In road 65 traffic, diesel is the most common engine type in heavy trucks, utility vehicles and nonroad mobile machinery due to its good operating efficiency. Despite this efficiency, the particulate emissions have been a major drawback of the diesel engine before 
growth of diesel particulate filter (DPF) use in road vehicles in developed markets. The introduction of the advanced aftertreatment systems, such as the DPF and diesel oxidation catalyst (DOC), have led to a decline of 20-65\% in black carbon (BC) emissions from heavy-duty road diesel engines in developed markets between 1990-2010 (Klimont et al., 2017). However,

70 Klimont et al. (2017) also reported a much slower reduction in less developed regions, which is due to less stringent emission regulations but likely also due to old vehicles being exported there near the end of their life span in the developed areas. Therefore, road vehicles without DPF or DOC are globally still widely used and will keep polluting urban environments for a long time, especially in developing countries. Although more sustainable and less polluting technologies to road transportation are being developed, the diesel engine is still about to maintain its global popularity for decades.

Diesel emissions can severely impair air quality in urban areas and thus adversely affect human health. Both the properties of the solid core particles and carcinogenic components adsorbed to the particles may affect the adverse effects (Bendtsen et al., 2020). These effects of diesel emissions are known; however, their total indirect climate effect, including the potential of diesel emission particles to act as INPs among other factors, remains less studied. In addition to that, substituting fossil diesel by renewable diesel fuels such as hydrotreated vegetable oil (HVO) and fatty acid methyl ester (FAME) type biodiesel, to mitigate $\mathrm{CO}_{2}$ emissions, changes the physicochemical characteristics of the diesel engine exhaust emissions (Dimitriadis et al., 2018; Giakoumis et al., 2012; Gren et al., 2020; Karavalakis et al., 2017; Murtonen et al., 2010). The HVO and FAME-type fuels can significantly reduce particulate matter (PM), hydrocarbon (HC), and carbon monoxide (CO) emissions in diesel exhaust (Giakoumis et al., 2012; McCaffery et al., 2020), as well as they impact the particle size distribution and soot nanostructure 85 (Lapuerta et al., 2008; Savic et al., 2016). To our knowledge, the number of previous studies focusing on the ice-nucleating potential of renewable diesel fuels (Schill et al., 2016; Chou et al., 2013) is limited.

Chou et al. (2013) used a continuous flow diffusion chamber (CFDC) to study the immersion freezing ice-nucleating potential of particles emitted from two small diesel engines belonging to a passenger car with a DOC and to a transporter without any aftertreatment, respectively. Freshly emitted particles and particles exposed to photochemical aging were studied at temperatures of $-35^{\circ} \mathrm{C}$ and $-30{ }^{\circ} \mathrm{C}$ and no immersion freezing was observed with one exception of a single measurement at $35^{\circ} \mathrm{C}$, where $\alpha$-pinene was added in the aging phase. Schill et al. (2016) used a similar CFDC set-up with a sample temperature of $-30{ }^{\circ} \mathrm{C}$, to study the immersion freezing ice-nucleating potential of freshly emitted and aged particles from a small diesel engine with combustion of diesel and biodiesel, respectively. They observed no concentrations of INPs that differed significantly from the background in any of the experiments. Kulkarni et al. (2016) studied the deposition freezing icenucleating potential at temperatures from $-50{ }^{\circ} \mathrm{C}$ to $-40{ }^{\circ} \mathrm{C}$ of fresh and aged diesel engine emissions and they reported heterogeneous freezing in many cases, where particle aging played an important role. The properties of particles emitted from diesel engines depend on (1) the engine, (2) engine operation, (3) the fuel and oil applied, (4) emission aftertreatment, and (5) atmospheric aging. Hence, it is necessary to study a wide variety of such different parameters, to fully assess the ice-nucleating potential of diesel engine emissions. 
The scope of this study is to report the immersion freezing ice-nucleating abilities of particulate emissions from a modern commercial heavy-duty diesel engine that was modified for single-cylinder operation. While smaller diesel engines may get replaced by more sustainable alternatives in near future, it is likely that heavy-duty diesel engines will be in use further than that. For the experiments, we used one fossil diesel and two different modern renewable diesel fuels, and two emission aftertreatment systems used both individually and combined; both fresh and photochemically aged particles were studied. We investigate the immersion freezing ability at temperatures down to where homogenous freezing dominates, to detect potentially low ice-nucleating abilities. Furthermore, we provide a detailed physicochemical characterization of the studied aerosol particles.

\section{Experiment methodology}

\subsection{Experiment set-up}

The experiments were conducted at the Combustion Engine Laboratory of Lund University. The test engine used was a sixcylinder inline Scania D13 heavy-duty diesel engine that was modified for single-cylinder operation. During the experiments, the engine was in a separate compartment of the laboratory and operated remotely from the control room. The standard

115 experiment procedure involved studies of fresh and aged emissions for the same engine operation. Our approach allowed for one full temperature scan with the CFDC for each particle type studied within a single experiment.

Figure 1 shows the sampling strategy for ice-nucleation experiments and collection of relevant supportive data. The set-up allowed multiple types of combinations for exhaust emission aftertreatment, secondary organic aerosol (SOA) production and simulated aging. For instance, the three different available aftertreatment types were 1) Engine-out (no aftertreatment), 2) DOC (Diesel Oxidation Catalyst), 3) DOC+DPF (Diesel Particulate Filter). After passing the aftertreatment system, the emissions were cooled down and diluted using a porous tube diluter and ejector dilution; the purpose of this was to simulate atmospheric dilution when the emission gases exit the exhaust pipe in real-life operation. The sample treatment section also enabled three different modes: 1) no treatment, 2) photochemical aging in potential aerosol mass oxidation flow reactor (PAM) and 3) thermodenuder after the PAM to remove volatile particle components. Before introduction to the CFDC and supportive instruments, the sample emissions were further diluted by 1:5-10 using dry compressed air and ejector dilution, to ensure desiccation down to $<10 \% R H_{\text {water }}$. In addition to ice-nucleation experiments with the CFDC, the following instruments were used for collection of supportive data: an SMPS system (classifier TSI 3082 equipped with aerosol neutralizer TSI 3088 and condensation particle counter - CPC, TSI 3775). The latter scanned continuously during experiments repeating $180 \mathrm{~s}$ scans

130 with a sample-to-sheath flow ratio of $0.3 \mathrm{~L} \mathrm{~min}^{-1}$ vs. $3 \mathrm{~L} \mathrm{~min}^{-1}$, respectively. The size range of the SMPS system was 11-500 $\mathrm{nm}$ and the automatic multiple charge correction of the software was used. A cloud condensation nuclei counter (CCNC, Droplet Measurement Technologies) was used in parallel with an aerosol particle mass analyzer (APM, Kanomax) to measure 
the cloud condensation nuclei $(\mathrm{CCN})$ activity $\left(\kappa_{\alpha}\right)$ and effective density ( $\left.\rho_{\text {eff }}\right)$ of the size-selected quasi-monodisperse particles,

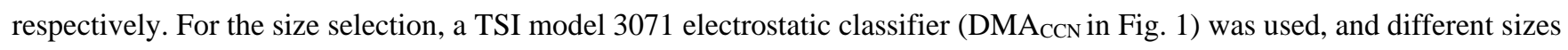
were selected via variation of DMA voltage during sampling. The emission sampling time of 30 minutes for each aftertreatment/sample treatment combination enabled three CCNC and APM scans for four different dry particle mobility diameters of about $60 \mathrm{~nm}, 100 \mathrm{~nm}, 200 \mathrm{~nm}$, and $300 \mathrm{~nm}$, respectively. A soot particle aerosol mass spectrometer (SP-AMS, Aerodyne inc.) was used for physicochemical analysis of the exhaust particles. Moreover, an aethalometer (Magee Scientific AE33, sampling rate $1 \mathrm{~Hz}$ ) measured soot optical properties, equivalent black carbon (eBC) and absorption Angstrom exponent (AAE). The eBC inferred from the aethalometer data were scaled to elemental carbon (EC) by dividing with a factor 2.8, described in detail by Gren et al. (2021). A detailed description of emission particle characterization methodology is presented in Sect. 2.3. For the CFDC experiments, the sample aerosol was desiccated to $<5 \% R H_{\text {water }}$, prior to introduction to the CFDC.

The engine test procedure comprised two phases: pre-heating (duration 1-1.5 hours) and then approximately 1.5 hours of emission sampling, during which freshly emitted and aged particles were sampled. The engine was considered warm when the cylinder head temperature reached $85^{\circ} \mathrm{C}$. During each experiment, the engine was operated at constant speed of $1200 \mathrm{rpm}$ and load of 6 bar gross indicated mean effective pressure, with common rail injection pressure being 2000 bar. A low level of exhaust gas recirculation (EGR) setting was used, 18\% oxygen on intake air to the combustion cylinder. The engine was lubricated with synthetic low-ash motor oil (Shell Mysella S3 N40) in all experiments. The fuels included EN 590 compliant ultra-low sulfur fossil diesel (Swedish classification MK1:B0), HVO and RME. It is worth emphasizing that all test fuels consisted of single component only and no fuel blends were tested.

\subsection{Ice-nucleation experiments}

The instrument used for the ice-nucleation experiments was the SPIN (Spectrometer for Ice Nuclei) which is a commercial ice nuclei (IN) counter manufactured by Droplet Measurement Technologies Inc., Colorado, USA (Garimella et al., 2016). The SPIN is a CFDC with parallel-plate chamber geometry similar to the Portable Ice Nuclei Chamber (PINC) introduced by Chou et al. (2011) and the Zurich Ice Nuclei Chamber (ZINC) described by Stetzer et al. (2008). During standard operation, the aerosol is sampled at the flow rate of 1 standard liter per minute (SLPM). When the sample flow passes the IN chamber, it is sandwiched between two sheath flows of 4.5 SLPM each, and the residence time inside the chamber is approximately 10 seconds. The freezing conditions are created via generating a diffusional flux of water vapor across the chamber by setting the ice-covered chamber plates to different sub-zero temperatures. The properties such as temperature, relative humidity, and the ideal path of the sample flow, from here on referred to as laminar flow, are modelled using a 1-D flow model by Rogers et al. (1988). Prior to detection by an optical particle counter (OPC), the aerosol passes through an isothermal evaporation section (residence time approximately 2 seconds) whose temperature was set to follow the average lamina temperature. Before starting the experiments, the instrument was prepared following the procedures introduced by Korhonen et al. (2020). The chamber was cooled down to $-32^{\circ} \mathrm{C}$ and filled with de-ionized water for 5 seconds to create a thin ice layer on both chamber plates, and 
after purging the chamber it was vacuumed down to $70 \mathrm{mbar}$ for $5 \mathrm{~min}$ to remove loose ice and make the ice layer smoother inside the IN chamber. This procedure reduced the background signal, i.e., unwanted ice crystal counts, significantly and it was typically less than 1 particle per liter in the beginning of experiments. The chamber was re-iced when the background signal exceeded 10-15 particles per liter. This practice, together with averaging the SPIN measurement data to 10-second periods, allowed minimum ice crystal detection limit (smallest detectable ice-activated fraction) in the order of $10^{-6}$ when the sample number concentrations were in the orders of $10^{3}-10^{4} \mathrm{~cm}^{-3}$, in a similar fashion to one used in transient experiments by Korhonen et al. (2020).

The ice-nucleation experiments were done using ascending T-scans (i.e., ramping the sample temperature upwards) at constant $R H_{\text {water }}=110 \%$, at temperatures from $-43^{\circ} \mathrm{C}$ to $-32^{\circ} \mathrm{C}$. This operation led to co-existence of liquid droplets and potential ice crystals under certain conditions. Although this approach focusing on immersion and condensation freezing only is uncommon for most CFDC studies, the approach and its advantages are discussed in more detail by Korhonen et al. (2020). The main motivation for this operation procedure is 1) to ensure that a significant number of particles with low CCN activity form droplets inside SPIN, and 2) that immersion freezing over a wider temperature range can be investigated. The co-existence of droplets and ice is due to the evaporation section of the SPIN, which is less efficient than for most other CFDCs (Garimella et al., 2017). Although it can be expected that the droplets shrink when passing the evaporation section, the residence time is insufficient to evaporate them completely. Therefore, we used basic size-separation for ice crystals and droplets. Korhonen et al. (2020) observed that when using this approach and no freezing takes place in the IN chamber, the maximum droplet size approaches $6 \mu \mathrm{m}$ even for particles with high hygroscopicity. Thus, we consider observed particles larger than $6 \mu \mathrm{m}$ ice crystals. The ice-activated fraction $\alpha$ is therefore defined as:

$$
\alpha=\frac{N_{i c e}}{N_{C P C}}
$$

where $N_{i c e}$ is the background-corrected number concentration of ice crystals detected by the OPC, from the combined sample and sheath flows exiting the IN chamber of the SPIN. The internal background signal of the SPIN was measured by sampling dry, filtered air for at least 5 minutes before initiation of the T-scan and again after the scan had finished. Background correction means subtraction of background counts from measured signal during these background checks, and the values between them (i.e., during the T-scans) were linearly interpolated to indicate the background signal also during sampling. $N_{C P C}$ is the number concentration of sample particles detected by the CPC, in parallel with the SPIN. The random uncertainty from CPC and OPC is estimated via assuming that the respective counts are randomly distributed, and their standard deviation equals to the inverse of the square root of counts. From that, the total random uncertainty was calculated via propagation of uncertainty, considering IN counts, IN background counts and total particle count as variables involved in definition of $\alpha$ (see Eq. 1). It is worth noting that this error analysis comprises only the statistical errors related to detection efficiency; the additional CFDC-related biases, 
such as particle losses at the laminar flow are discussed in detail by Korhonen et al. (2020). In this study, we define ice onset as an ice-activated fraction of $10^{-3}$ which is a commonly used threshold in the literature.

Table 1 summarizes the experiments on different fuels and aftertreatment combinations. We report a total of 15 experiments which were conducted with the SPIN, and polydisperse aerosol was sampled in each of them during engine operation. The particle number size distributions all had maxima for sizes well below $100 \mathrm{~nm}$, with a tail towards larger sizes. The sampled particle number concentration was diluted to $5000-20000 \mathrm{~cm}^{-3}$ before introduction to the SPIN (marked 'dilution' in Fig. 1), depending on sample treatment; higher number concentrations were used in experiments involving the PAM with extensive formation of new relatively small secondary aerosol particles. It is known that too high sample particle number concentrations may lead to depletion of water vapor inside a CFDC (Levin et al., 2016), while too low number concentrations reduce the measurement sensitivity. The motivation of choosing a relatively high sample concentration was that most of the particles were rather small and/or hydrophobic, so water vapor depletion due to cloud droplet activation inside the CFDC is not expected to be significant, which will be discussed in more detail in Sect. 3.1. For comparison to homogeneous freezing, a homogeneous freezing test of liquid droplets was conducted on quasi-monodisperse $350 \mathrm{~nm}$ dry electrical mobility ammonium sulfate (AS) particles that were introduced to the SPIN in a number concentration of approximately $150 \mathrm{~cm}^{-3}$.

215 We report the ice-nucleation results and their respective comparisons to the homogeneous freezing test in two different calculation methods. The first method indicates observed ice crystal number concentration divided by total sample concentration by the CPC (see eq. 1): this presents the INP potential normalized to the whole particle population. Secondly, we present results normalized to the highest achieved ice-active fraction in each experiment and compare them to the homogeneous freezing test: the purpose of this calculative test is to estimate the immersion freezing ability of the subset of particles facilitating droplet formation inside the CFDC. We expect this particle fraction to be dominated by the larger particles, since they are more likely to act as CCN. A large fraction of the particle population is assumed to consist of particles that 1) are too small and too hydrophobic to act as CCN inside the CFDC and 2) have insufficient surface area to nucleate ice, yet they become detected by the CPC. The normalization was calculated via averaging the five highest observed ice-activation fractions (typically at $-41.5 \pm 0.3^{\circ} \mathrm{C}$, thus significantly below homogeneous freezing temperature) from each experiment, and linearly scaling the activation spectra to coincide at sample temperature of $-41.5 \pm 0.3{ }^{\circ} \mathrm{C}$.

\subsection{Emission particle characterization}

To characterize the studied emission particles, we used the supportive instrumentation (see Fig. 1) and inferred the following particle properties. The CCNC was operated in flow scan mode with the same approach as used by Korhonen et al. (2020) and described in more detail by Kristensen et al. (ACPD, 2020). Briefly, quasi-monodisperse particle populations with mobility 230 diameters of about 58, 107, 196 and at times $296 \mathrm{~nm}$, respectively, were selected with the DMACCN (see Fig. 1). The particles were introduced into the $\mathrm{CCNC}$ and the supersaturation was scanned by up-scans in the flow rate linearly from 0.20 to 1.0 
$\mathrm{L} / \mathrm{min}$. The total flowrate of the CCNC set-up was maintained at $1.0 \mathrm{~L} / \mathrm{min}$ by operating a mass-flow controller (MFC) in parallel with the $\mathrm{CCNC}$ with flow rates decreasing from 0.8 to $0.0 \mathrm{~L} / \mathrm{min}$ during a CCNC up-scan. The temperature gradient along the CCNC column was kept constant during scans at either $10{ }^{\circ} \mathrm{C}$ or $18{ }^{\circ} \mathrm{C}$ allowing for a full range of supersaturations from about 0.15 to $2.4 \%$. The supersaturations of the $\mathrm{CCNC}$ were calibrated with ammonium sulfate particles immediately prior to the campaign, and the calibration curves were similar to the ones obtained by Kristensen et al. (ACPD, 2020). The apparent hygroscopicity, parameter $\kappa_{\alpha}$, was inferred from the CCNC data following Petters and Kreidenweis (2007). In many cases, the supersaturation did not suffice to activate the studied particles, and results are presented only when a full CCN spectrum could be identified.

The aethalometer measured the attenuation of light at seven wavelengths 370-950 nm, from which the absorption Angstrom exponent (AAE) was inferred. The aethalometer eBC concentration yielded values with a factor of $\sim 2.8 \pm 0.6$ higher compared to elemental carbon (EC) concentrations (variability $<25 \%$ between replicates). Therefore, the eBC concentrations of this study have been scaled to $\mathrm{EC}$ by dividing the $\mathrm{eBC}$ abundance by an empirical correction factor 2.8 , specific to this campaign (Gren et al., 2021). The particle effective density was inferred from the APM data according to the method applied by Rissler et al. (2013) and Korhonen et al. (2020). The SP-AMS data provided information on chemical composition of particles and qualitative markers on the relative abundance of refractory oxygen (for instance, on particle surface) and presence of immature (disordered) carbon nanostructures in the soot (Malmborg et al., 2019). For organic quantification, we used unit mass resolution data from "tungsten only vaporization mode", i.e., the soot module was not engaged, with the default relative ionization efficiency of 1.4. The results for soot oxides and nanostructure were recorded in dual vaporizer mode. Data analysis was performed using PIKA 1.22A and SQUIRREL 1.62A. The instrument was calibrated with nebulized and DMA selected 300 $\mathrm{nm}$ mobility equivalent diameter ammonium nitrate particles, by comparing ion rates with particle concentrations measured with a CPC. The ratio between organics and equivalent black carbon (OA/eBC) was calculated from SP-AMS and aethalometer data.

\section{Results}

\subsection{Particle size distributions}

Figure 2 and Table 1 show that the diesel engine emissions were heavily dominated by ultrafine $(<100 \mathrm{~nm})$ particles by number in all experiments, regardless of fuel, aging or aftertreatment used. The size distributions were commonly bimodal. The geometric mean diameter of nucleation and soot modes were typically around $15 \mathrm{~nm}$ and $50 \mathrm{~nm}$ in dry electrical mobility, respectively, for fresh (unaged) emissions. Aging with the oxidation flow reactor commonly grew the nucleation mode particles to larger sizes, while use of the diesel oxidation catalyst (DOC) in the exhaust aftertreatment system and use of the thermal denuder in the sampling system reduced the concentration of nucleation mode particles. Gren et al. (2021) present a more comprehensive description of the particle size distributions. Use of the renewable fuels (HVO, RME) led to a reduction of soot 
mode number emissions of $20 \%$ for $\mathrm{HVO}$ and $56 \%$ for RME, as well as an $\mathrm{eBC}$ reduction of approximately $50 \%$ was observed for both fuels compared to fossil diesel per MJ (Gren et al., 2021). In this study, the soot mode GMDs were slightly smaller for HVO $(40 \mathrm{~nm})$ compared to fossil diesel and RME $(50 \mathrm{~nm})$, which means that the soot reduction of HVO originate from both a reduced soot particle size as well as a reduced number concentration, while the soot reduction of RME are dominated by the reduced number concentration. Thermodenuder treatment $\left(250^{\circ} \mathrm{C}\right)$ removed a significant fraction of the SOA emissions.

Particles larger than $100 \mathrm{~nm}$ accounted typically for less than $10 \%$ of the whole number concentration (see Table 1). Regarding the high sample concentrations introduced to the SPIN, the largest $>100 \mathrm{~nm}$ particles represented number concentrations up to approximately $1200 \mathrm{~cm}^{-3}$, implying a reasonable detection sensitivity. The fraction of particles larger than $250 \mathrm{~nm}$ was near negligible, in the order of $10^{-4}$ from total sampled concentration. Due to this, we discuss the ice-nucleating abilities of the studied emissions in two different calculating methods for ice-activated fraction in the following section: first, we report the results relative to whole sample population of polydisperse aerosol. This indicates the overall ice-nucleating ability of diesel soot emissions. Second, we use an alternative method where the ice-activated fractions are normalized by the highest observed ice-active fraction below the homogeneous freezing temperature. The purpose of this alternative approach was to estimate the immersion freezing ability of the particles which acted as CCN inside the CFDC. Hence, the first approach (when other biases are corrected) describes the overall effect of (1) droplet formation in combination with (2) immersion freezing for the entire particle population, while the alternative approach only relates to the immersion freezing ability of the subset of particles facilitating droplet formation inside the CFDC, most likely dominated by the larger particles.

\subsection{Ice-nucleation}

We present the results from ascending T-scans on the SPIN and compare them to homogeneous freezing test on AS droplets. In addition to that, we estimate the potential contributions of soot-mode particles to the observed total IN activity. The emissions from fossil diesel are presented in Figs. 3-4, the former showing results without photochemical aging and latter with the PAM and PAM+TD. We found that the fresh, unaged emissions from fossil diesel were inactive INPs in both engine-out and DOC experiments: when the whole sample population (panel a) in Fig.3) is considered, the IN activity does not appear significantly higher than for the homogeneous freezing reference. However, it should be noted that for an average lamina temperature of $-41^{\circ} \mathrm{C}$, the ice-active fraction potentially is more than an order of magnitude lower than for the homogeneous freezing reference; we ascribe this to a pronounced fraction of the studied particles being too small and/or too hydrophobic to facilitate droplet formation. When the ice-activation spectra were normalized (Fig. 3.b), two of the samples appear to facilitate heterogeneous ice-nucleation at approximately $1{ }^{\circ} \mathrm{C}$ higher temperature than homogeneous freezing reference, with the observations thus showing only modest heterogeneous IN activity. Furthermore, this supports the second assumption that was used for justification of the normalization test: regarding the ultrafine particles typically comprised up to more than $90 \%$ of

295 the whole sample number concentration, it can be expected that particles with little surface area have passed through the SPIN without any detectable effect. The error analysis confirms that the observed differences to homogeneous freezing are outside 
of the estimated instrument uncertainty in both experiments with the DOC (red and green dots and green shaded area in panel b) of Fig. 3).

Photochemical aging was found to have little effect on ice-activity, as Fig. 4 shows: for the whole sample population, the most ice-active case produced ice onset at approximately $0.5^{\circ} \mathrm{C}$ higher temperature than homogeneous freezing. The normalization test revealed that the highest activity was only slightly higher than in unaged emissions $\left(1.2{ }^{\circ} \mathrm{C}\right.$ vs. $0.6{ }^{\circ} \mathrm{C}$, relative to the homogeneous freezing reference), which indicates that the simulated photochemical aging through $\mathrm{OH}$ and $\mathrm{O}_{3}$ exposure has some, but only little effect on IN activity of fossil diesel emissions. The aged samples showed similar behavior in ice-activity relative to the unaged ones, with maximum activated fraction reaching up to $1.7 \%$ from whole sample population, regardless of the equivalent atmospheric aging time. Generally, the ice-activated fractions never reached above $1.7 \%$ in any experiment on polydisperse sample emissions from fossil diesel.

The HVO produced emission particles that were ice-active at less than $0.5^{\circ} \mathrm{C}$ higher than homogeneous freezing and thus, there is no indication of significant heterogeneous ice-nucleation within the instrument uncertainty range as panel a) of Fig.5 shows. It is also obvious that neither different aftertreatment methods nor photochemical aging affected the ice-activity outside of instrument uncertainty boundaries. In this case too, the studied particles show very low total activation at the very lowest temperatures, similar to fossil diesel emissions: when the whole particle population is taken into account, only up to $2.2 \%$ (see green dots in panel a) of Fig. 5) of total number concentration activated as ice: this indicates again that the ultrafine mode particles likely had very little contribution to the $\mathrm{CCN}$-active subset of the particle population. The situation, however, changed with the normalization test: unlike with fossil diesel, the $10^{-3}$ ice-activated fraction was reached at $-36.1{ }^{\circ} \mathrm{C}$ which was already outside of instrument uncertainty. Therefore, the CCN-active emissions from the HVO were apparently slightly more iceactive than the ones from fossil diesel. Despite this observed higher ice-activity, the emissions from the HVO still appear as poor INPs and thus their role in heterogeneous ice-nucleation in the atmosphere is likely a minor one. The present global usage of biodiesel components mostly in fuel blends only, together with fossil diesel, diminishes the potential of this slightly higher ice-activity when compared to pure fossil diesel fuel (see Fig. 3).

Finally, we present the observations from the RME emissions in Fig. 6. With normalization to the entire polydisperse particle population (Fig. 6.a), there is no significant indication of heterogeneous freezing, and the ice-active fractions appear very low for the lowest temperatures. The total activation to ice crystals is much less prominent than with fossil diesel and HVO, with the most active case (see green dots in panel a) of Fig. 6) producing a maximum of only $0.7 \%$, well below the homogeneous freezing temperature. The least active case was entirely untreated emission (red dots in panel a) of Fig. 6) with only $0.1 \%$ being observed as ice below $-40{ }^{\circ} \mathrm{C}$ sampling temperature. This can be due to differences in size distributions (see the left-hand panel of Fig. 2): the fraction of ultrafine particles is much larger by number in experiments without aftertreatment ('engineout' and 'engine-out with the PAM'). At any rate, this again agrees with the minor role of ultrafine particles in ice-nucleation. 
The normalization test showed that all studied RME particle emissions that would contribute to ice formation facilitated the ice-active fraction of $10^{-3}$ at $1^{\circ} \mathrm{C}$ higher temperature than what is required for homogeneous freezing, which indicates that the studied RME emissions are inefficient INPs.

\subsection{Emission particle properties}

335 In addition to ice-nucleation experiments, we investigated several physical and chemical properties of the sample particles using the supportive instrumentation, and Table 2 shows the studied properties of the particles in this study. The CCNC experiments showed no CCN activity in any experiment without the PAM, which is a clear indicator of extreme hydrophobicity of the studied particles that was also observed in the SPIN as weak droplet formation despite high supersaturation $R H_{\text {water }}=$ $110 \%$ during the T-scans. The PAM experiments where SOA formation on diesel emission particles took place increased the

$340 \kappa_{\alpha}$ values to distinguishable levels, yet this increased hygroscopicity had no observed effect on ice-activity. This suggests that the SOA coating has little or no effect on ice-activity on the studied diesel emission particles, as we observed between the PAM experiments on the three studied fuels. The AAEs and presented ion ratios indicate mature soot particles typical for diesel engine emissions. Notably the ratio $\mathrm{C} 3 \mathrm{O} 2 / \mathrm{C} 3$ was higher here for each sample compared with those found for solid biomass fuel combustion in Korhonen et al. (2020), which indicates the diesel soot was more oxidized in this study. The

345 exhaust from fossil diesel combustion after simulated atmospheric aging and without emission aftertreatment was dominated by secondary organic mass (SOA). RME and to a lesser extent HVO produced eBC mixed with SOA. All experiments except aged fossil diesel and aged $\mathrm{HVO}+$ engine-out provided eBC-dominated emissions.

\section{Summary, discussion, and conclusions}

We measured the ice-nucleating abilities of particulate emissions from three different types of diesel fuel using different emission aftertreatment methods and found that fresh emissions were inefficient INPs in immersion and condensation icenucleation modes at temperatures relevant to MPC conditions. All fuels were tested without blending, which enabled investigation on fossil and biodiesel fuels separately. The ice-nucleation results agree with previous studies on diesel emissions [Chou et al., 2013; Schill et al., 2016], and we conclude that the studied diesel emission particles are poor INPs in general. Besides, our results are in complete agreement with Kanji et al. (2020) who studied whether hydrocarbon soot from propane 355 combustion and different commercially available black carbon particles can induce immersion freezing and found all of them inefficient ice-nucleators. We also found that photochemical aging increased the IN activity on fossil diesel, but no distinguishable effect was found on the other fuels, HVO and RME. The observed differences from unaged emissions, however, were almost negligible and therefore, we conclude that photochemical aging had little or no effect on the IN activity of studied emissions. With these observations altogether, it can be implied that the emissions from the studied diesel fuels produce no significant number concentrations of INPs to the atmosphere. Moreover, all emissions were by number dominated by ultrafine particles which clearly had no contribution to ice-nucleation. In addition to that, the extreme hydrophobicity that 
was observed in both CCNC and SPIN experiments may explain the generally poor IN activity to an extent. The alternative method we used for calculating the ice-activated fraction, i.e., normalization to highest INP production below homogeneous freezing temperature, revealed only a small change in comparison to considering the whole particle population. The only exception to this was for the HVO fuel whose emissions may have a slight potential as active INPs. For fossil diesel and RME, only modest increase in IN activity was observed via this alternative calculation method. This calculative test supports the conclusion on observed poor IN ability of the particles in general. Regarding that all single-component fuels of this study produced similar results, it can be expected that fuel blends from similar components also produce no or few active INPs.

It is worth mentioning that all experiments in this study were conducted under well-controlled laboratory conditions and using the test engine on its optimal operation settings in all experiments. Contrary to that, the emission particle properties may differ in real-life use of diesel engines, depending on factors such as engine model and age, technical condition of the engine, fuel quality and varying load during the operation. Other aging effects, in addition to studied photooxidation, may affect the IN abilities of emission particles. Old diesel vehicles and fuels with e.g. much higher sulfur content, which all are still commonly used in the developing parts of the world may produce different types of PM emissions; this link should be explored before evaluating the total global climate effect.

Data availability. Data sets are available from the authors upon request.

380 Author contribution. TBK planned the ice-nucleation experiment methodology on the SPIN instrument, which was operated by KK during the campaign. AL, AV, JF, KK, MK and TBK participated in data analysis of ice-nucleation experiments and/or interpretation of results. AE, JF, JP, LM, LG, PK, TBK and VBM participated in collection of supportive data and/or interpretation of results. JP, MT, PK, SS and VMB designed the experiment matrix for the engine, the aftertreatment systems and the fuels used in this study. MN and SS operated the diesel engine during the campaign and performed its maintenance, with assistance by LM and PK. BS, JP and MT participated as the organizers and supervisors of the experiment campaign. All authors participated in scientific discussions on this study and reviewed/edited the manuscript during its preparation process. KK prepared the manuscript with contributions from all co-authors.

Competing interests. The authors declare that they have no conflict of interest.

Acknowledgements. Thomas Bjerring Kristensen gratefully acknowledges funding from the Swedish Research Council VR (grant 2017-05016). Joakim Pagels, Louise Gren, Vilhelm B. Malmborg and Axel Eriksson acknowledge funding from the Swedish Research Council FORMAS (grant 2016-00697) and the Swedish Research Council VR (grant 2018-04200). We thank Vikram Singh for technical assistance in diesel engine operation. 


\section{References}

Bendtsen, K. M., Gren, L., Malmborg, V. B., Shukla, P. C., Tunér, M., Essig, Y. J., Krais, A.M., Clausen, P.A., Berthing, T., Loeschner, K., Jacobsen, N.R., Wolff, H., Pagels, J. and Vogel, U.B., Particle characterization and toxicity in C57BL/6 mice following instillation of five different diesel exhaust particles designed to differ in physicochemical properties, Part. Fibre. Toxicol., 17, 18. doi: 10.1186/s12989-020-00369-9, 2020.

Bond, T.C., Doherty, S.J., Fahey, D.W., Forster, P.M., Berntsen, T., DeAngelo, B.J., Flanner, M.G., Ghan, S., Kärcher, B., Koch, D., Kinne, S., Kondo, Y., Quinn, P.K., Sarofirm, M.C., Schultz, M.G., Schulz, M., Venkataraman, C., Zhang, H., Zhang, S., Bellouin, N., Guttikunda, S.K., Hopke, P.K., Jacobson, M.Z., Kaiser, J.W., Klimont, Z., Lohmann, U., Schwarz, J.P., Shindell, D., Storelvmo, T., Warren, S.G. and Zender, C.S., Bounding the role of black carbon in the climate system: A scientific assessment, J. Geophys. Res. Atmos., 118, 5380-5552, doi:10.1002/jgrd.50171, 2013.

Boucher, O., Randall, D., Artaxo, P., Bretherton, C., Feingold, G., Forster, P., Kerminen, V-M., Kondo, Y., Liao, H., Lohmann, U., Rasch, P., Satheesh, S.K., Sherwood, S., Stevens, B. and Zhang, X.Y.: Clouds and Aerosols. In: Climate Change 2013: The Physical Science Basis. Contribution of Working Group I to the Fifth Assessment Report of the Intergovernmental Panel on Climate Change [Stocker, T.F., D. Qin, G.-K. Plattner, M. Tignor, S.K. Allen, J. Boschung, A. Nauels, Y. Xia, V. Bex and P.M. Midgley (eds.)]. Cambridge University Press, Cambridge, United Kingdom and New York, NY, USA, 2013.

Chou, C., Stetzer, O.,Weingartner, E., Jurányi, Z., Kanji, Z. A., and Lohmann, U.: Ice nuclei properties within a Saharan dust event at the Jungfraujoch in the Swiss Alps, Atmos. Chem. Phys., 11, 4725-4738, doi: 10.5194/acp-11-4725-2011, 2011.

415 Chou, C., Kanji, Z. A., Stetzer, O., Tritscher, T., Chirico, R., Heringa, M. F., Weingartner, E., Prévôt, A. S. H., Baltensperger, U., and Lohmann, U.: Effect of photochemical ageing on the ice nucleation properties of diesel and wood burning particles, Atmos. Chem. Phys., 13, 761-772, https://doi.org/10.5194/acp-13-761-2013, 2013.

Davis, S. C., Williams, S. E. and Boundy, R. G., Transportation energy data book edition 36. ORNL/TM-2017/513. Oak Ridge, 420 TN: Prepared by Oak Ridge National Laboratory for U.S. Department of Energy., http://cta.ornl.gov/data/tedb36/Edition_36_Full_Doc.pdf, accessed October 14, 2020.

DeMott, P., An exploratory study of ice nucleation by soot aerosols, J. Appl. Met., 29, 1072-1079, 1990.

425 DeMott, P.J., Chen Y., Kreidenweis, S.M., Rogers, D.C. and Sherman D.E., Ice formation by black carbon particles, Geophys. Res. Letters, vol. 26, no. 16, 2429-2432, 1999. 
DeMott, P. J., M. D. Petters, A. J. Prenni, C. M. Carrico, S. M. Kreidenweis, J. L. Collett Jr., and H. Moosmüller, Ice nucleation behavior of biomass combustion particles at cirrus temperatures, J. Geophys. Res., 114, D16205, doi:10.1029/2009JD012036, 2009.

DeMott, P. J., Prenni, A.J., Liu, X., Kreidenweis, S.M., Petters M.D., Twohy, C.H., Richardson, M.S., Eidhammer, T., and Rogers, D.C., Predicting global atmospheric ice nuclei distributions and their impacts on climate, PNAS, 107, 11217-11222, https://doi.org/10.1073/pnas.0910818107, 2010.

Després, V., Huffman, J., Burrows, S., Hoose, C., Safatov, A., Buryak, G., Fröhlich-Nowoisky, J., Elbert, W., Andreae, M., Pöschl, U. and Jaenicke, R., Primary biological aerosol particles in the atmosphere: a review. Tellus B, 64. doi: http://dx.doi.org/10.3402/tellusb.v64i0.15598, 2012

440 Diehl, K and Mitra, S.K.: A laboratory study of the effects of a kerosene-burner exhaust on ice nucleation and the evaporation rate of ice crystals, Atmos. Env., 32, 18, 3145-3151,1998.

Dimitriadis, A., Natsios, I., Dimaratos, A., Katsaounis, D., Samaras, Z., Bezergianni, S. and Lehto, K.: Evaluation of a Hydrotreated Vegetable Oil (HVO) and Effects on Emissions of a Passenger Car Diesel Engine, Front. Mech. Eng., 4, 1-19, doi:10.3389/fmech.2018.00007, 2018.

Dymarska, M., Murray, B. J., Sun, L., Eastwood, M. L., Knopf, D. A. and Bertram, A.K., Deposition ice nucleation on soot at temperatures relevant for the lower troposphere, J. Geophys. Res., 111, D04204, doi:10.1029/2005JD006627, 2006.

Garimella, S., Kristensen, T. B., Ignatius, K.,Welti, A., Voigtländer, J., Kulkarni, G. R., Sagan, F., Kok, G. L., Dorsey, J., Nichman, L., Rothenberg, D., Rösch, M., Kirchgäßner, A., Ladkin, R., Wex, H., Wilson, T. W., Ladino, L. A., Abbatt, J. P. D., Stetzer, O., Lohmann, U., Stratmann, F., and Cziczo, D. J.: The Spectrometer for Ice Nuclei (SPIN): An instrument to investigate ice nucleation,

Atmos. Meas. Tech., 9, 2781-2795, doi: 10.5194/amt-9-2781-2016, 2016.

Garimella, S., Rothenberg, D. A., Wolf, M. J., David, R. O., Kanji, Z. A., Wang, C., Rösch, M., and Cziczo, D. J.: Uncertainty in counting ice nucleating particles with continuous flow diffusion chambers, Atmos. Chem. Phys., 17, 10855-10864, doi: 10.5194/acp-17-10855-2017, 2017. 
460 Giakoumis, E. G., Rakopoulos, C. D., Dimaratos, A. M. and Rakopoulos, D. C.: Exhaust emissions of diesel engines operating under transient conditions with biodiesel fuel blends, Prog. Energy Combust. Sci., 38, 691-715, doi:10.1016/j.pecs.2012.05.002, 2012.

Gorbunov, B., Baklanov, A., Kakutkina, N., Windsor, H.L. and Toumi, R., Ice nucleation on soot particles, Aer. Sci., 32, 199465 215, doi: 10.1016/S0021-8502(00)00077-X, 2001.

Gren, L., Malmborg, V. B., Jacobsen, N. R., Shukla, P. C., Bendtsen, K. M., Eriksson, A. C., Essig, Y. J., Krais, A. M., Loeschner, K., Shamun, S., Strandberg, B., Tunér, M., Vogel, U. and Pagels, J.: Effect of renewable fuels and intake O2 concentration on diesel engine emission characteristics and reactive oxygen species (ROS) formation, Atmosphere (Basel), 11, doi:10.3390/atmos11060641, 2020.

Gren, L., Malmborg, V.B., Falk, J., Markkula, L., Novakovic, M., Shamun, S., Eriksson, A., Kristensen, T.B., Svenningsson, B., Tunér, M., Karjalainen, P. and Pagels, J., Effects of renewable fuel and exhaust aftertreatment on primary and secondary emissions from a modern heavy-duty diesel engine, J. Aerosol Sci., under peer-review as of $5^{\text {th }}$ February 2021.

Hoose, C. and Möhler, O.: Heterogeneous ice nucleation on atmospheric aerosols: a review of results from laboratory experiments, Atmos. Chem. Phys., 12, 9817-9854, doi:10.5194/acp-12-9817-2012, 2012.

Häusler, T., Gebhardt, P., Igleasias, D., Rameshan, C., Marchesan, S., Eder, D. and Grothe, H., Ice Nucleation Activity of Graphene and Graphene Oxides, J. Phys. Chem. C 2018, 122, 15, 8182-190, doi: 10.1021/acs.jpcc.7b10675, 2018.

Kanji, Z. A., Welti, A., Corbin, J. C., and Mensah, A. A., Black carbon particles do not matter for immersion mode ice nucleation. Geophys. Res. Lett., 46, e2019GL086764, doi:10.1029/2019GL086764, 2020.

485 Karavalakis, G., Gysel, N., Schmitz, D. A., Cho, A. K., Sioutas, C., Schauer, J. J., Cocker, D. R. and Durbin, T. D.: Impact of biodiesel on regulated and unregulated emissions, and redox and proinflammatory properties of PM emitted from heavy-duty vehicles, Sci. Total Environ., 584-585, 1230-1238, doi:10.1016/j.scitotenv.2017.01.187, 2017.

Klimont, Z., Kupiainen, K., Heyes, C., Purohit, P., Cofala, J., Rafaj, P., Borken-Kleefeld, J., and Schöpp, W.: Global 490 anthropogenic emissions of particulate matter including black carbon, Atmos. Chem. Phys., 17, 8681-8723, doi: 10.5194/acp17-8681-2017, 2017. 
Koehler, K.A., DeMott, P.J., Kreidenweis, S.M., Popovicheva, O.B., Petters, M.D., Carrico, C.M., Kireeva, E.D., Khoklova, T.D. and Shonija, N.K., Cloud condensation nuclei and ice nucleation activity of hydrophobic and hydrophilic soot particles,

Phys. Chem. Chem. Phys., 2009, 11, 7906-7920, 2009.

Koop, T., Luo, B., Tsias, A., and Peter, T.: Water activity as the determinant for homogeneous ice nucleation in aqueous solutions, Nature, 406, 611-614, 2000.

500 Korhonen, K., Kristensen, T. B., Falk, J., Lindgren, R., Andersen, C., Carvalho, R. L., Malmborg, V., Eriksson, A., Boman, C., Pagels, J., Svenningsson, B., Komppula, M., Lehtinen, K. E. J., and Virtanen, A.: Ice-nucleating ability of particulate emissions from solid-biomass-fired cookstoves: an experimental study, Atmos. Chem. Phys., 20, 4951-4968, https://doi.org/10.5194/acp-20-4951-2020, 2020.

505 Kristensen, T. B., Falk, J., Lindgren, R., Andersen, C., Malmborg, V. B., Eriksson, A. C., Korhonen, K., Carvalho, R. L., Boman, C., Pagels, J., and Svenningsson, B.: Properties and emission factors of CCN from biomass cookstoves - observations of a strong dependency on potassium content in the fuel, Atmos. Chem. Phys. Discuss., https://doi.org/10.5194/acp-2020-893, in review, 2020 .

510 Kulkarni, G., Swarup, C., Liu, S., Nandasiri, M., Sharma, N., Wilson, J., Aiken, A.C., Chand, D., Laskin, A., Mazzoleni, C., Pekour, M., Shilling, J., Shutthanadan, V., Zelenyuk, A. and Zaveri, R.A., Ice nucleation activity of diesel soot particles at cirrus relevant temperature conditions: Effects of hydration, secondary organics coating, soot morphology, and coagulation, Geophys. Res. Lett., 43, doi:10.1002/2016GL068707, 2016.

515 Lapuerta, M., Armas, O. and Rodríguez-Fernández, J.: Effect of biodiesel fuels on diesel engine emissions, Prog. Energy Combust. Sci., 34, 198-223, doi:10.1016/j.pecs.2007.07.001, 2008.

Levin, E. J. T., McMeeking G.R., DeMott, P.J., McCluskey C.S., Carrico C.M., Nakao S., Jayrathne T., Stone E.A., Stockwell C.E., Yokelson R.J. and Kreidenweis S.M., Ice-nucleating particle emissions from biomass combustion and the potential importance of soot aerosol, J. Geophys. Res. Atmos., 121, 5888-5903, doi:10.1002/2016JD024879, 2016.

Mahrt, F., Marcolli, C., David, R. O., Grönquist, P., Barthazy Meier, E. J., Lohmann, U., and Kanji, Z. A.: Ice nucleation abilities of soot particles determined with the Horizontal Ice Nucleation Chamber, Atmos. Chem. Phys., 18, 13363-13392, https://doi.org/10.5194/acp-18-13363-2018, 2018. 
Malmborg, V. B., Eriksson, A. C., Török, S., Zhang, Y., Kling, K., Martinsson, J., Fortner, E.C., Gren, L., Kook, S., Onasch, T.B., Bengtsson, P-E. and Pagels J.: Relating aerosol mass spectra to composition and nanostructure of soot particles. Carbon, 142, 535-546, doi: 10.1016/j.carbon.2018.10.072, 2019.

530 Mao, J., Ren, X., Brune, W. H., Olson, J. R., Crawford, J. H., Fried, A., Huey, L. G., Cohen, R. C., Heikes, B., Singh, H. B., Blake, D. R., Sachse, G. W., Diskin, G. S., Hall, S. R. and Shetter, R. E.: Airborne measurement of OH reactivity during INTEX-B, Atmos. Chem. Phys., 9, 163-173, doi:10.5194/acp-9-163-2009, 2009.

McCaffery, C., Karavalakis, G., Durbin, T., Jung, H. and Johnson, K.: Engine-Out Emissions Characteristics of a Light Duty 535 Vehicle Operating on a Hydrogenated Vegetable Oil Renewable Diesel, SAE Tech. Pap., 1-11, doi:10.4271/2020-01-0337, 2020.

Murray, B.J., O’Sullivan, D., Atkinson, J.D., Webb, M.E., Ice nucleation by particles immersed in supercooled cloud droplets, Chem. Soc. Rev., 41, 6519-6554, doi: 10.1039/C2CS35200A, 2012.

Murtonen, A. T., Kuronen, M., Mikkonen, S., Lehtoranta, K., Sae, S., Journal, I. and Murtonen, T.: Emissions with Heavyduty Diesel Engines and Vehicles using FAME, HVO and GTL Fuels with and without DOC + POC Aftertreatment, Em, 2, $147-166,2010$.

545 Mülmenstädt, J., Sourdeval, O., Delanoë, J., and Quaas, J. (2015), Frequency of occurrence of rain from liquid-, mixed-, and ice-phase clouds derived from A-Train satellite retrievals, Geophys. Res. Lett., 42, 6502- 6509, doi:10.1002/2015GL064604.

Möhler, O., Büttner S., Linke C., Schnaiter M., Saathoff H., Stetzer O., Wagner R., Krämer M., Mangold A., Ebert V. and Shurath U., Effect of sulfuric acid coating on heterogeneous ice nucleation by soot aerosol particles, J. Geophys. Res., 110, D11210, doi:10.1029/2004JD005169, 2005.

Petters, M. D. and Kreidenweis, S. M.: A single parameter representation of hygroscopic growth and cloud condensation nucleus activity, Atmos. Chem. Phys., 7, 1961-1971, doi:10.5194/acp-7-1961-2007, 2007.

555 Pruppacher, H. R. and Klett, J. D.: Microphysics of Clouds and Precipitation, Atmospheric and Oceanographic Sciences Library, Kluwer Academic Publishers, Dordrecht, the Netherlands, 1997. 
Rissler, J., Messing, M. E., Malik, A. I., Nilsson, P. T., Nordin, E. Z., Bohgard, M., Sanati, M and Pagels, J.: Effective density characterization of soot agglomerates from various sources and comparison to aggregation theory. Aer. Sci. Tech., 47(7), 792805, doi: 10.1080/02786826.2013.791381, 2013.

Rogers, D. C.: Development of a continuous flow thermal gradient diffusion chamber for ice nucleation studies, Atmos. Res., 22, 149-181, 1988.

565 Savic, N., Rahman, M. M., Miljevic, B., Saathoff, H., Naumann, K. H., Leisner, T., Riches, J., Gupta, B., Motta, N. and Ristovski, Z. D.: Influence of biodiesel fuel composition on the morphology and microstructure of particles emitted from diesel engines, Carbon N. Y., doi:10.1016/j.carbon.2016.03.061, 2016.

Schill, G.P., Jathar, S.H., Kodros, J.K., Levin, E.J.T., Galang, A.M., Friedman, B., Link, M.F., Farmer, D.K., Pierce, J.R., 570 Kreidenweis, S.M. and DeMott, P.J.: Ice-nucleating particle emissions from photochemically aged diesel and biodiesel exhaust, Geophys. Res. Letters., 43, 5524-5531, doi: 10.1002/2016GL069529, 2016.

Stetzer, O., Baschek, B., Lüönd, F., and Lohmann, U.: The Zurich Ice Nucleation Chamber (ZINC) - a new instrument to investigate atmospheric ice formation, Aerosol Sci. Tech., 42, 64-72,

5752008.

Vali, G., DeMott, P.J., Möhler O. and Whale, T.F., Technical Note: A proposal for ice nucleation terminology, Atmos. Chem. Phys., 15, 10263-10270, doi:10.5194/acp-15-10263-2015, 2015.

Vergara-Temprado, J., Holden, M.A., Orton, T.R., O’Sullivan, D., Umo, N.S., Browse, J., Reddington, C., Baeza-Romero, 580 M.T., Jones, J.M., Lea-Langton, A., Williams, A., Carslaw, K.S. and Murray, B.J., Is Black Carbon an Unimportant IceNucleating Particle in Mixed-Phase Clouds?, J. Geophys. Res., 123, 4273-4283, doi: 10.1002/2017JD027831, 2018.

Yun, Y., Penner, J.E. and Popovicheva, O.: The effects of hygroscopicity on ice nucleation of fossil fuel combustion aerosols in mixed-phase clouds, Atmos. Chem. Phys., 13, 4339-4348, doi: 10.5194/acp-13-4339-2013, 2013. 


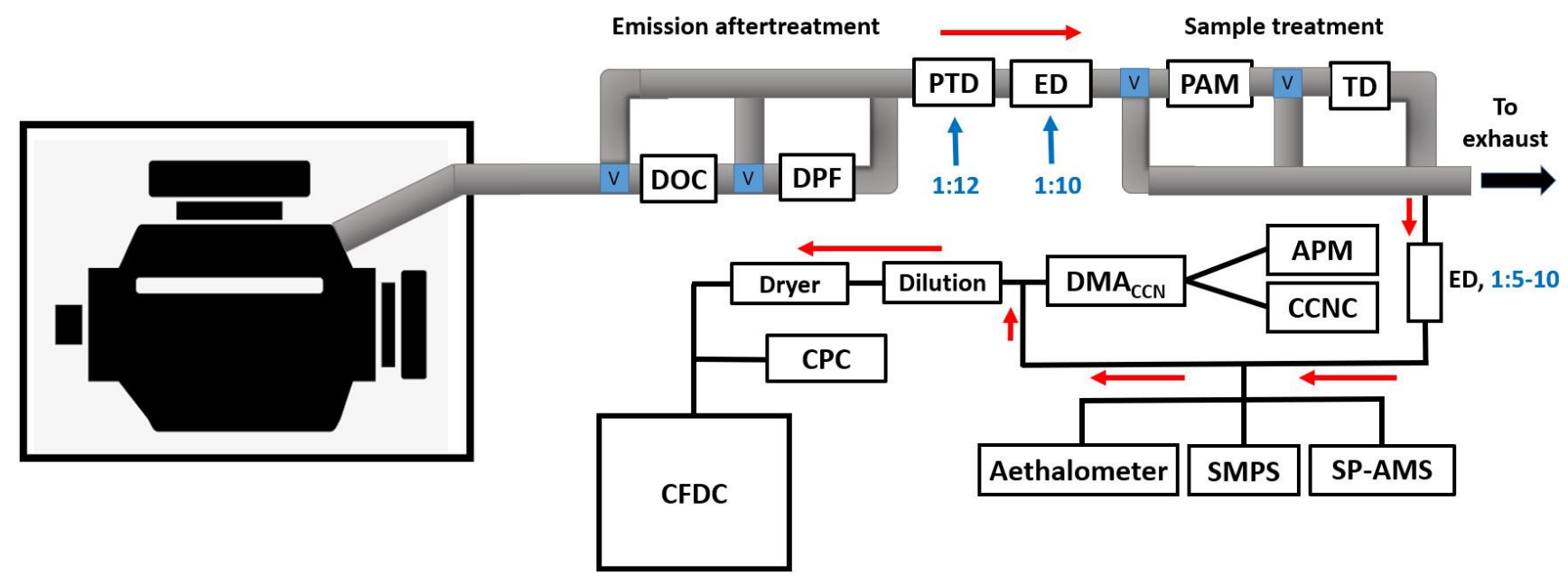

Figure 1: Schematic of the sampling strategy relevant for the IN experiments. Blue squares with letter "V" indicate valves to change between different sampling modes. The red arrows indicate direction of sample flow. The acronyms are defined as follows: APM = aerosol particle mass analyzer, $\mathrm{CCNC}=$ cloud condensation nuclei counter, $\mathrm{CFDC}=$ continuous-flow diffusion chamber, $\mathrm{CPC}=$ condensation particle counter, $\mathrm{DOC}=$ diesel oxidation catalyst, $\mathrm{DMA}=$ differential mobility analyzer, $\mathrm{DPF}=$ diesel particulate filter, ED = ejector dilution, FPA = fast particle analyzer, PAM = potential aerosol mass oxidation flow reactor, $P$ TD = porous tube diluter, SMPS = scanning mobility particle sizer, SP-AMS = soot particle aerosol mass spectrometer and TD = thermodenuder. The dimensions and sample line lengths are not in same dimensions to one another. 
https://doi.org/10.5194/acp-2021-111

Preprint. Discussion started: 26 February 2021

(c) Author(s) 2021. CC BY 4.0 License.

(c) (i)
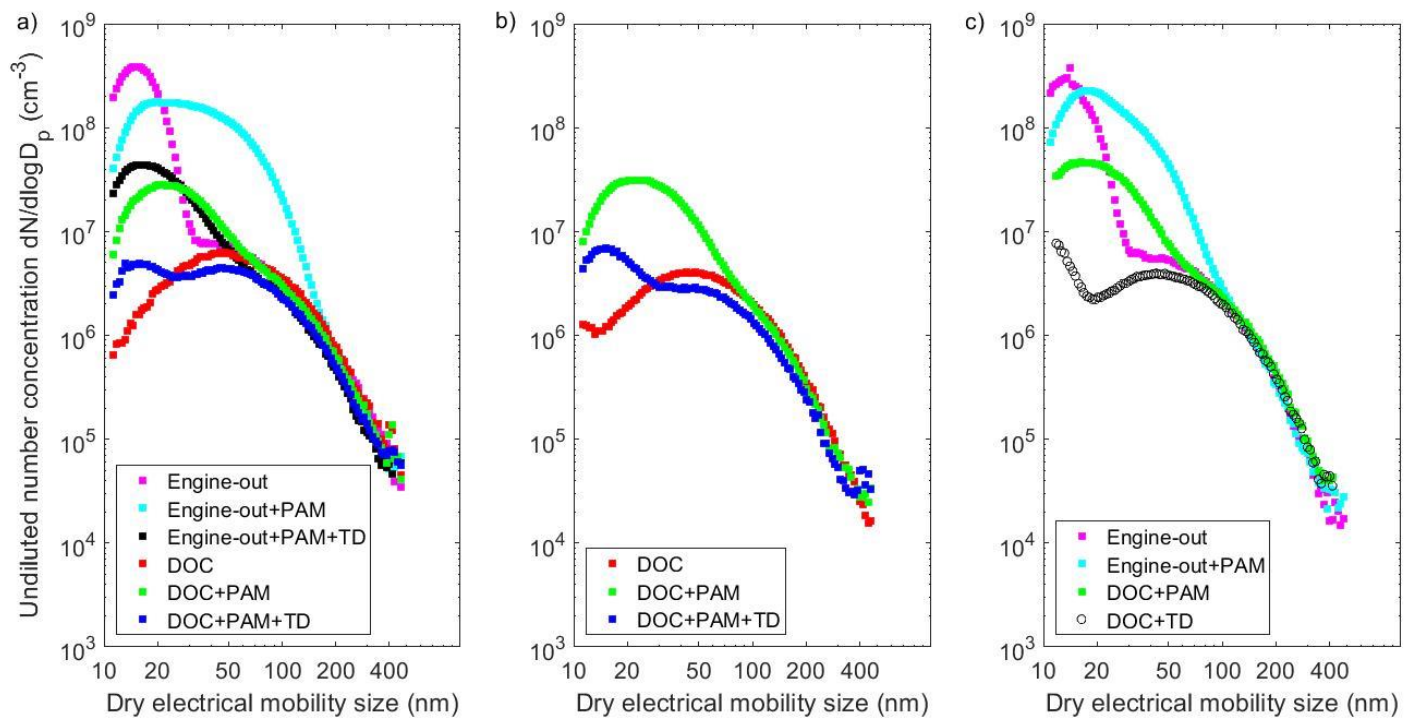

Figure 2: Number size distributions of sampled emissions, convereted to represent an undiluted situation: panels a), b) and c) present the results for fossil diesel, HVO and RME, respectively. The number concentrations represent the average that was measured during the engine operation period in each experiment. "Engine-out" refers to a case without emission aftertreatment. See Gren et al. (2021) for a more detailed analysis on emission particle properties of this study. 
a)

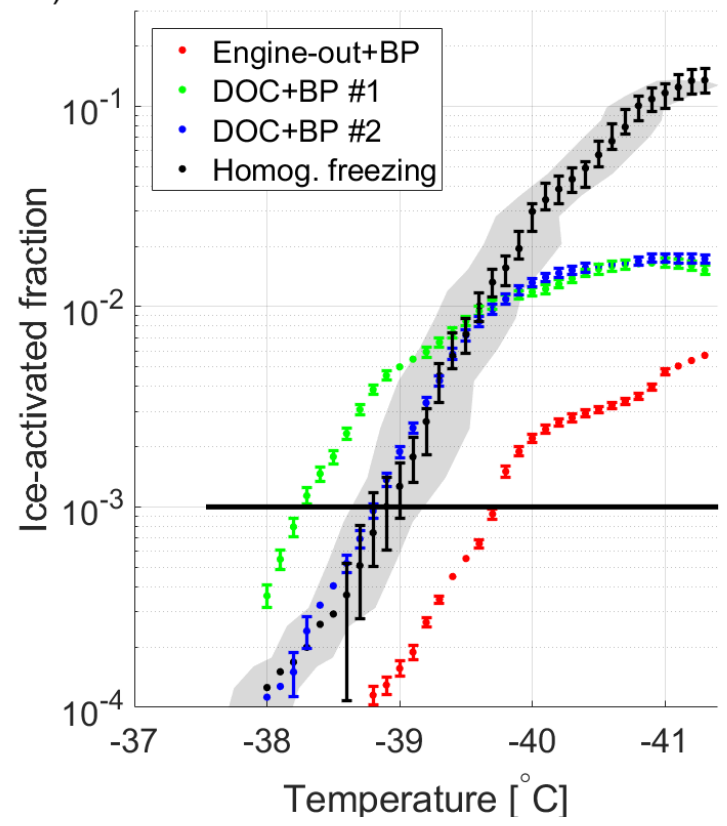

b)

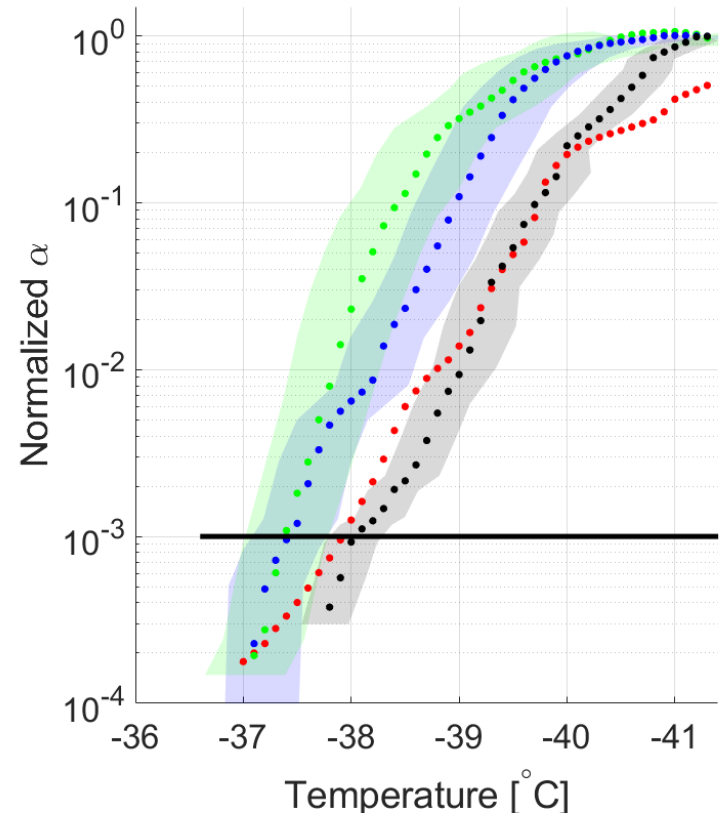

Figure 3: Ice-activation spectra of unaged fossil diesel emissions without photochemical aging at $\boldsymbol{R} \boldsymbol{H}_{\text {water }}=\mathbf{1 1 0 \%}$, compared to homogeneous freezing test of droplets. The error bars represent the random error from detectors (two standard deviations), and the shaded areas of respective colors represent the $\mathbf{T}$-span on the lamina during the experiments. The solid black line indicates $0.1 \%$ activated fraction. Panel a) presents the ice-activation of whole sample population (polydisperse aerosol), and panel b) a situation where all activation spectra are normalized to the highest ice-activation fraction from each respective experiment. "Engine-out" refers to a case without emission aftertreatment, and BP = bypass (sample treatment method). 
a)

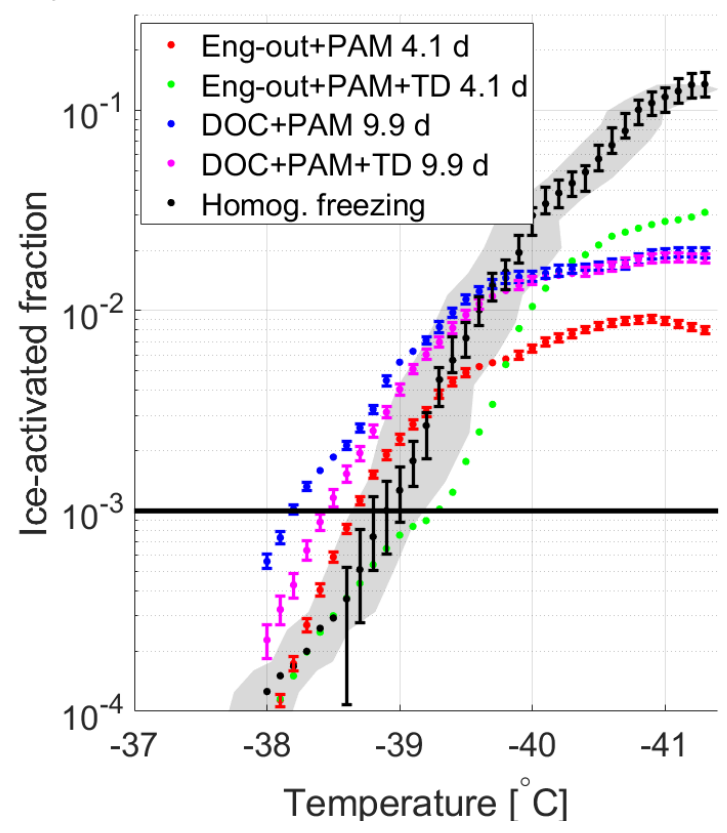

b)

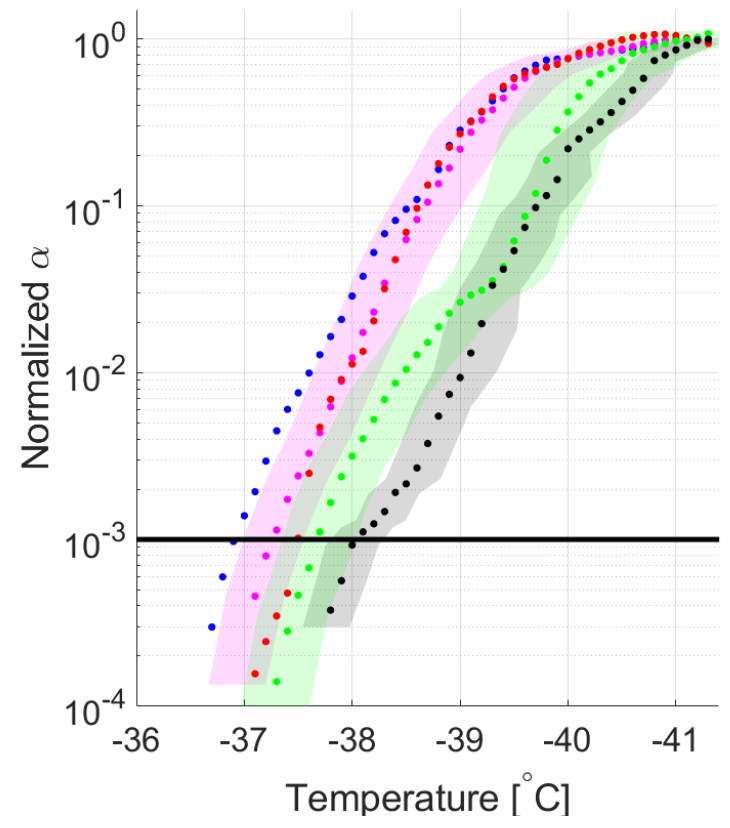

Figure 4: Ice-activation spectra of fossil diesel emissions with two different photochemical aging levels at $R H_{\text {water }}=110 \%$, compared to homogeneous freezing test of droplets. The error bars represent the random error from detectors (two standard deviations), and the shaded areas of respective colors represent the $\mathrm{T}$-span on the lamina during the experiments. The solid black line indicates $0.1 \%$ activated fraction. Panel a) presents the ice-activation of whole sample population (polydisperse aerosol), and panel b) a situation where all activation spectra are normalized to the highest ice-activation fraction from each respective experiment. "Eng-out" refers to a case without emission aftertreatment. 
a)

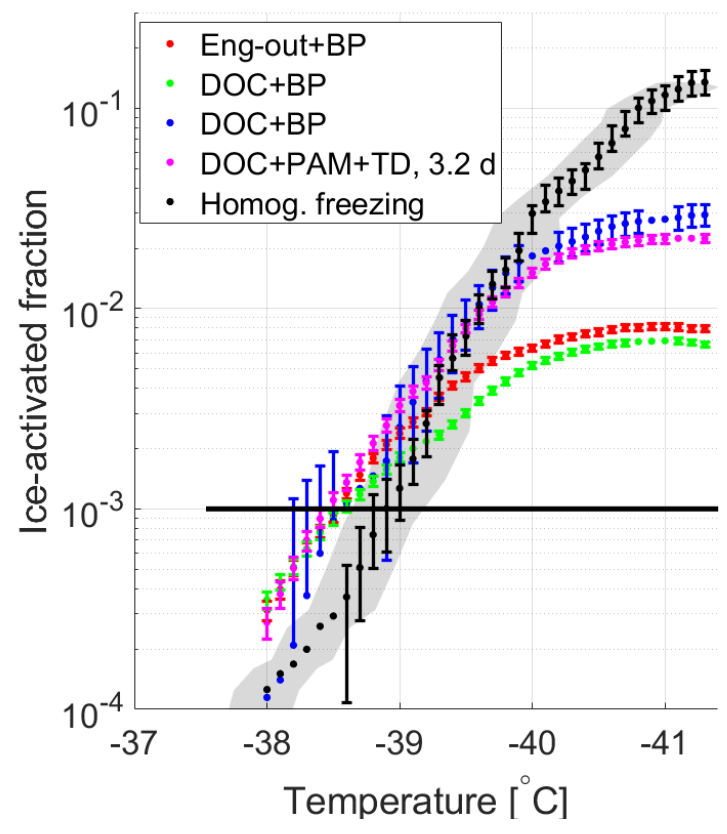

b)

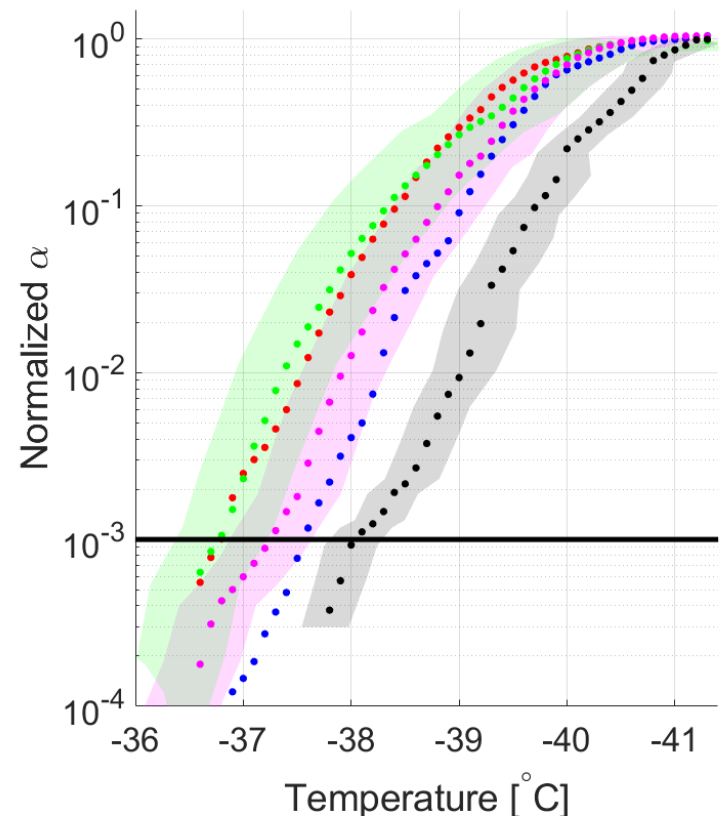

Figure 5: Ice-activation spectra of HVO emissions at $\mathbf{R H}_{\text {water }}=\mathbf{1 1 0} \%$, compared to homogeneous freezing test of droplets. The shaded areas of respective colors represent the $T$-span on the lamina during the experiments. The error bars represent the random error from detectors (two standard deviations), and the shaded areas of respective colors represent the $T$-span on the lamina during the experiments. The solid black line indicates $0.1 \%$ activated fraction. Panel a) presents the ice-activation of whole sample population (polydisperse aerosol), and panel b) a situation where all activation spectra are normalized to the highest ice-activation fraction from each respective experiment. "Eng-out" refers to a case without emission aftertreatment, and BP = bypass (sample treatment method). 
a)

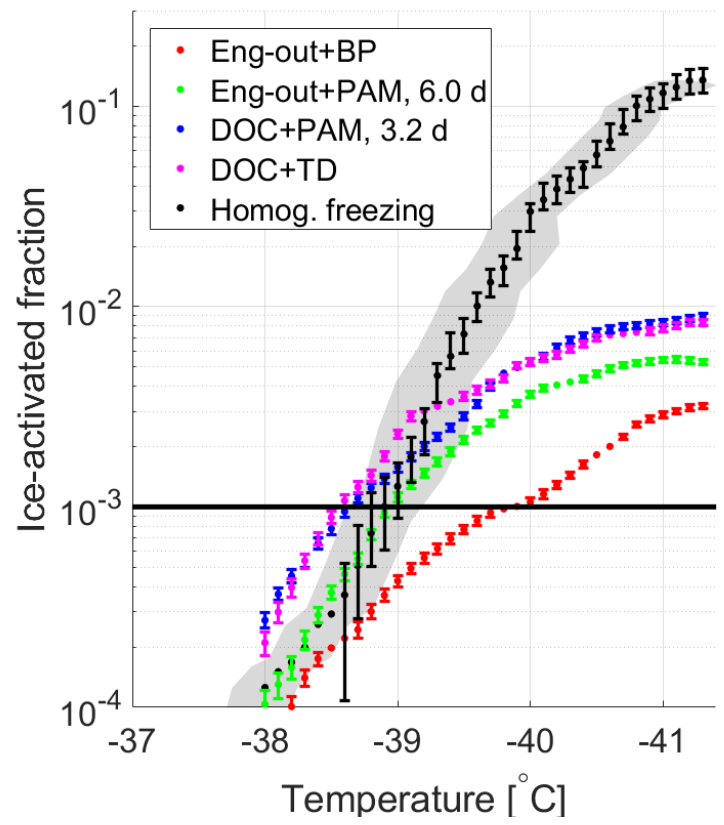

b)

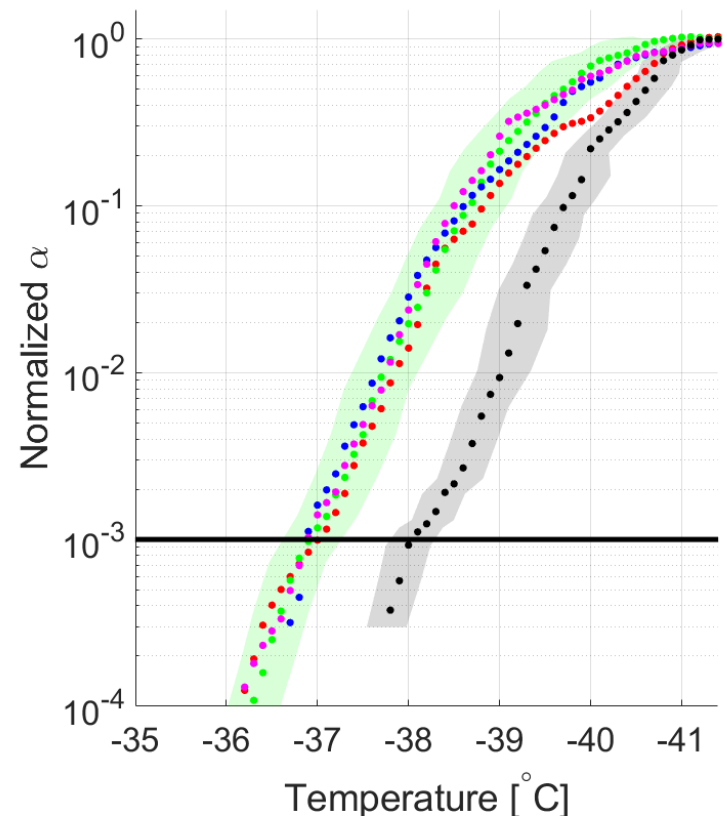

Figure 6: Ice-activation spectra of RME emissions at $\boldsymbol{R H}_{\text {water }}=\mathbf{1 1 0} \%$, compared to homogeneous freezing test of droplets. The error bars represent the random error from detectors (two standard deviations), and the shaded areas of respective colors represent the T-span on the lamina during the experiments. The solid black line indicates $0.1 \%$ activated fraction. Panel a) presents the iceactivation of whole sample population (polydisperse aerosol), and panel b) a situation where all activation spectra are normalized to the highest ice-activation fraction from each respective experiment. "Eng-out" refers to a case without emission aftertreatment, and BP = bypass (sample treatment method). 
Table 1: Summary of experiments on different aftertreatment and sample treatment combinations and photochemical aging levels. The PAM aging refers to equivalent atmospheric aging due to photooxidation in days, when average atmospheric $O H$ concentration of $1.5 \times 10^{6}$ molecules $\mathrm{cm}^{-3}$ is assumed following Mao et al. (2009).

\begin{tabular}{|c|c|c|c|c|}
\hline Fuel & $\begin{array}{c}\text { Emission } \\
\text { aftertreatment }\end{array}$ & $\begin{array}{c}\text { Sample } \\
\text { treatment }\end{array}$ & $\begin{array}{l}\text { PAM } \\
\text { aging } \\
\text { [days] }\end{array}$ & $\begin{array}{l}\text { Fraction of 11- } \\
100 \mathrm{~nm} \\
\text { particles [\%] }\end{array}$ \\
\hline Fossil diesel & engine-out & bypass & - & 98.4 \\
\hline Fossil diesel & engine-out & PAM & 4.1 & 97.8 \\
\hline Fossil diesel & engine-out & PAM+TD & 4.1 & 97.8 \\
\hline Fossil diesel & DOC & bypass & - & 84.4 \\
\hline Fossil diesel & DOC & bypass & - & 84.4 \\
\hline Fossil diesel & DOC & PAM & 9.9 & 96.3 \\
\hline Fossil diesel & $\mathrm{DOC}$ & PAM+TD & 9.9 & 89.2 \\
\hline HVO & engine-out & bypass & - & - \\
\hline $\mathrm{HVO}$ & DOC & bypass & - & 87.7 \\
\hline $\mathrm{HVO}$ & DOC & PAM & - & 98.0 \\
\hline $\mathrm{HVO}$ & $\mathrm{DOC}$ & PAM+TD & 3.2 & 93.5 \\
\hline $\mathrm{RME}$ & engine-out & bypass & - & 99.4 \\
\hline RME & engine-out & PAM & 6.0 & 99.6 \\
\hline RME & DOC & PAM & 3.2 & 98.1 \\
\hline $\mathrm{RME}$ & $\mathrm{DOC}$ & $\mathrm{TD}$ & - & 89.8 \\
\hline
\end{tabular}


Table 2: Physical and chemical properties of studied particles: hygroscopicity parameter $\kappa \alpha$ for scanned sample particle sizes, absorption Angstrom exponent (AAE), fraction of surface oxides $\left(\mathrm{C}_{3} \mathrm{O}_{2} / \mathrm{C}_{3}\right)$, fraction of mid-range carbon elements $\left(\mathrm{C}_{11} / \mathrm{C}_{3}\right)$, abundance of organic aerosol (OA) and OA-to-BC ratio. Empty entries indicate unavailable/unreliable data.

\begin{tabular}{|c|c|c|c|c|c|c|c|c|}
\hline Fuel & $\begin{array}{c}\text { Emission } \\
\text { aftertreatment }\end{array}$ & $\begin{array}{c}\text { Sample } \\
\text { treatment }\end{array}$ & $\begin{array}{c}\kappa_{\alpha} \\
(58 \mathrm{~nm} / 107 \mathrm{~nm} / 196 \mathrm{~nm})\end{array}$ & $\mathbf{A A E}$ & $\mathrm{C}_{3} \mathrm{O}_{2} / \mathrm{C}_{3}$ & $\mathrm{C}_{11} / \mathrm{C}_{3}$ & $\begin{array}{c}\text { OA } \\
{\left[\mu \mathrm{g} \mathrm{m}^{-3}\right]}\end{array}$ & OA/eBC \\
\hline Fossil diesel & engine-out & bypass & N/A & 1.23 & 0.016 & 0.024 & 118 & 0.147 \\
\hline Fossil diesel & engine-out & PAM & $0.09 / 0.08 / 0.01$ & 1.24 & - & - & 2339 & 3.440 \\
\hline Fossil diesel & engine-out & PAM+TD & N/A & 1.18 & - & 0.015 & 90 & 0.174 \\
\hline Fossil diesel & $\mathrm{DOC}$ & bypass & N/A & 1.17 & 0.018 & 0.023 & 84 & 0.098 \\
\hline Fossil diesel & DOC & bypass & N/A & 1.17 & 0.018 & 0.023 & - & - \\
\hline Fossil diesel & DOC & PAM & $0.08 / 0.04 / 0.007$ & 1.19 & 0.020 & 0.019 & 153 & 0.239 \\
\hline Fossil diesel & DOC & PAM+TD & N/A & 1.19 & 0.013 & - & 87 & 0.160 \\
\hline $\mathrm{HVO}$ & engine-out & bypass & N/A & - & - & - & 87 & 0.189 \\
\hline HVO & DOC & bypass & N/A & 1.20 & - & - & 46 & 0.116 \\
\hline HVO & $\mathrm{DOC}$ & PAM & $0.10 / 0.04 /-$ & 1.22 & - & 0.014 & 104 & 0.309 \\
\hline HVO & DOC & PAM+TD & N/A & 1.20 & 0.017 & 0.008 & 21 & 0.078 \\
\hline RME & engine-out & bypass & N/A & 1.26 & - & - & 62 & 0.115 \\
\hline RME & engine-out & PAM & $0.09 / 0.04 / 0.01$ & - & - & 0.032 & 409 & 0.845 \\
\hline RME & $\mathrm{DOC}$ & PAM & N/A & - & - & - & 73 & 0.170 \\
\hline RME & $\mathrm{DOC}$ & TD & N/A & - & - & - & 22 & 0.057 \\
\hline
\end{tabular}

